\title{
COMMUNICATION, CHRONEMICS, SILENCE LANGUAGE
}

\author{
Florentina Pîrjol \\ West University of Timisoara, Timisoara, Romania \\ Faculty of Economics and Business Administration \\ florentina.pirjol@e-uvt.ro \\ Daiana-Elena lonesc \\ West University of Timisoara, Timisoara, Romania \\ Faculty of Economics and Business Administration \\ elena.ionesc98@e-uvt.ro
}

\begin{abstract}
The communication exists whenever a social entity can affect another and alter its reactions by transmitting information not by direct action. The word communication has a very broad meaning; it encompasses all the processes whereby a spirit can affect another spirit. Obviously, it includes not only written or spoken language, but also music, visual arts, theatre, ballet and, in fact, all human behaviors. Communication is the result of a relationship, regardless of the period related to the relationship. This form of relationship is built from the first contact, from a first impression, thus evolving through words chosen on the basis of reason or emotion, which can be decisive in this regard.
\end{abstract}

Keywords: Communication, concept, non-verbal communication languages

\section{INTRODUCTION}

The study of the communication process, the analysis of the main forms of communication, the definition of communication tools in an organization is a necessity emanates from the fact that we live in a universe laden with symbols and meanings in which, In order to be understood, in order to be able to correlate our actions, we need a common language field.

The communication is a complex process whose analysis requires the consideration of several particularities, so Stanton $(1995,36)$ distinguished the following peculiarities:

- The role of communication to put people in touch with each other, depending on the environment in which they evolve;

- The content of the message is intended to transmit certain meanings and to achieve certain purposes in the communication process;

- Any communication process has a triple dimension: communication externally (verbal and nonverbal actions observable by the interlocutors), Metacommunication (which is beyond 
words) and intra-Community (communication by the Each individual on the inside, at the level of the self);

- Any communication process is photography in a context, namely in a particular business, social, cultural, physical or temporal space;

- The communication process has a dynamic character because the communication once initiated, has a certain evolution, changes and changes and the people involved in the process;

- The communication process is irreversible in the sense that once the message is transmitted, it can no longer be stopped.

\section{COMMUNICATION, CHRONEMICS, SILENCE LANGUAGE}

\subsection{Communication concept}

In the life of all days, for the vast majority of people, communicating means "to make acquaintance" or "to inform". In this context, the use of the term of communication does not raise any particular problems. The apparent simplicity of this concept does not exclude the need to clarify the scientific significance of the communication.

Specialists believe that the beginning of the study of the communication process dates back to our era (Prutianu, 1998). The same author mentions that in ancient Greece there were laws that provided that every citizen would be his own lawyer. Those who best mastered the art of communication became political leaders and were part of the leadership of society.

For the ancients the symbol of communication was Hermes, considered a mediator between humans and deities.

It seems that the first elements of the theory of communication were written by Corax from Syracuse, in the "Art of Rhetoric". The study of rhetoric was subsequently developed by Plato who introduced this discipline into Greek academic life alongside philosophy.

Later, Aristotle wrote the first logical treaty-Organon-in which he laid the foundations for reasoning by using syllogism.

Syllogism is a speech in which, if something has been given, something other than the DAT follows with necessity from what has been given. From the phrase "from what has been given" there is always a consequence, and from the latter, that there is no need for any other term in Out to make the necessary consequence (Aristotle, 1997). Mircea Florian (Aristotle, 1997) specifies that from this definition we deduce that syllogism is a rigorous deductive reasoning, which does not use in any of its moments a subconscious foreign sentence. 
After the Greek-Roman era, the theory of human communication has not known significant progress for many centuries (Prutianu, idem).

Since 1600, due to the diminishing of the church's soil in society, the emergence of democratic regimes, universities, the issue of communication is beginning to occupy an increasingly important place in social life.

The modern era is characterized by the explosion of mass media and multiple transformations caused by the transition from the industrial society to the information society.

The literature highlights the fundamental role of the media in the structure of society and in the quality of inter-human relations.

Technological evolution divides the history of humanity into three distinct periods (Mc. LUHAN, 1967):

-the "tribal" period, in which the structure of the company was based on direct relations between individuals, without any technical input;

-the "Gutenberg" period, characterized by the dynamics of writings favored by the advent of printing;

-The period "Marconi" or the era of television which, through technology, establishes direct relations between people, across the globe.

In the Western world, considerations relating to media functions stand under the sign of "social media responsibility Theory". Formulated in the late ' 40 in the United States, this theory was leaving an immediate context and was a reaction to all sorts of media imputations: Whether it was partinic, whether it served exclusively to commercial interests (Cuillenburg, 1991). "Social Responsibility of the press" as a theory has crystallized as a result of a longer historical process, constituting a response to the liberal attitudes of the NINETEENTH century.

The debate on clarifying the notion of "communication" is characterized by the difference of perception horizons between specialists.

Sociologist Denis Mc. QUAIL (1999) believes that only in the appearance of society is a static source of social institutions; In reality, it is reanimated or expressed to the creator every day by private acts of a communicative nature that occur between the individuals who make it.

Viewed from a traditional sociological perspective, the act of communication is conditional on the existence of the following factors:

-proximity, i.e. nearby persons are more likely to communicate with each other than remote ones; -similarity, namely those in the same social circumstances or which share interests, beliefs, activities are more likely to communicate than those who differ from this point of view;

-group membership with the significance that the direction of the communicational flow is modeled by the relative status of the group members and their different roles. 
Where communication between individuals tends to recur can be talked about the existence of a communication channel (Mcquail, idem). This is the result of the existence of a physical infrastructure, a similarity of the participants in the Act of communication.

The same author mentions that a prerequisite for participation in social life is the possession of means of communication which includes an ensemble of languages and other symbolic systems. They play an essential role in the communication process by making the success or failure of its finality. If in the past the communicational discontinuities were often the result of cultural and social differences, nowadays they are increasingly associated with economic and power discrepancies.

The dictionary defines the communication as "the action to convey, to acknowledge, to divide, to be in relation to, to be bound, to be in relation to". This definition includes two distinct meanings: on the one hand, communicating means acting (transmitting, sharing, giving), and on the other hand, communication expresses a state (being in relation to, being related to).

Landry (1995) specifies that the term of communication originates from the Latin "communication" and has the significance of action by which a message is transmitted. According to this author, communication means a set of significant transactions between a message transmitter subject and an interlocutor to whom attention is sought and/or an explicit or implied response.

In a systemic vision (Moles, 1990), communication is defined as the action to trigger the response of a system located at a point, to stimuli emitted by another system located in another place, using known information on both sides.

Other authors (Marin, 1987) concern communication as a set of physical and psychological processes that perform the operation in relation to one or more persons in order to obtain certain objectives.

Marin (idem) states that between communication and communications there are substantive differences: communication is a fundamental feature of the human being and expresses the universal, as opposed to communication that refers to the tools, techniques and technologies that facilitate and amplify the process of communicating between individuals and between the authorities, giving them, in certain cases, a mass character.

The literature shows that the term of communication must be replaced by the phrase "global communication" which has a wider area of coverage than communication, calling for all means of expression, both those characteristic of the group communication and the outside of a collective (. Giordan, 1987).

In everyday life, information is used as a synonym of communication. The science of communication distinguishes between the two terms, considering information as a raw material in the communication 
process. In this respect, the information is defined as a combination of signals and symbols that gain significance based on social conventions (Cuilenburg, 1991).

Considered as a system, as a self-regulating entity, the organization is centered on the concepts of cybernetics and Information (Shannon, 1963). Studies on the analysis of organizations highlight that their effectiveness is directly proportional to the characteristics of the process of transmitting information.

A synthesis of research aimed at the impact of information technology on organizations communication, relies the fact that there are doubts about the capacity of human technology (Shannon, 1990).

\subsection{Chronemics}

Of all the resources people use to carry out their work in good condition, one is distributed equally to all: time. ${ }^{*}$ (https://dorinadanila.com/2015/08/25/ Time-language /).

What's the time? A good immaterial, irreversible and nonstock.

Chronemics or time language includes the use of time, status and cultural differences in message communication.

Time or chronemics can be used very differently in terms of individuals and even cultures. The perception of time includes punctuality, willingness to wait and interactions. The use of time affects lifestyles, daily agendas, speed of speech and movement, while people are willing to listen, etc. The way time is used can give information about people as individualities. There are different perceptions of the use of time and its value. Cultures also differ in terms of use of time. For example, in European and American societies, when men interact with women, they generally control the use of time, talk more than women, and interrupt more than women. In the business world, Americans will get to meetings on time and usually earlier. On the other hand, they arrive late at parties and evenings. A tip for managers: When debating the problem of time and punctuality, be very precise in explaining what this "on time" means. An employee can see acceptable arriving at work at 8:05 - 8:10, while the manager sees the time of 8:10 as late. By specifying an exact hour from the use of general phrases, communication can be improved and possible conflicts avoided.

Chronemics involve the use of time to communicate nonverbal. The message is that the subordinates are waiting for the superior and the superiors are not waiting for the subordinates. If you have a meeting with your teacher at 14:00 and you don't show up to 14:15 you better prepare your apologies for the teacher's precious time loss. If you appeared at 14:00 and the teacher only arrives at 14:15, on the other hand, he will not apologize for your loss of precious time. For example, Richard Nixon often did Congress and the heads of State to await him as a sign of power. 
Chronemics is determined culturally. The concept of time varies from one culture to another. In Mexican culture, if you invite someone to dinner, you don't give him a certain hour to arrive. In business communication It is important to know how to appreciate the differences. American businessmen are known to expect the business to end immediately, on the spot. In many cultures in Europe as in Japan expect a determined time to be given to socialization before the end of the business.

Another way of perception of time:

- Americans have the type of time M or monochromatic time that emphasizes schedules, appointments, segmentation and promptness.

- In the Middle East and Latin America use polychromatic time is characterized by the fact that several things are carried out at once.

- The Germans and the Swiss do not miss the opportunity to comment on Americans and time management.

The time as a symbol is also marked by its rhythm. Thus, the seasons impose certain activities, the holidays and rituals are marked by time, the working week also has a rhymicity. * (https://dorinadanila.com/2015/08/25/ Time-language/)

Time is perceived differently from the multitude of societies and cultures. In our culture we divided time into years, each having 365 days, while the Muslim year is 10-11 days shorter. Our years are counted from the year of birth of Jesus Christ, while the Muslim calendar begins Dina year 622 in which Mahomed fled Mecca to Medina (so in 1979, Muslims began their 14th century). Even inside the same crop, different communities can divide the time in different ways. (A trader divides his time into periods: Christmas, summer sales, holidays, etc. A farmer based on agricultural activity and seasons - time to plowing, sowing time and harvest time). The different values we give to time are reflected in the words we use ("Only one Minute", for example, can mean "one minute", "When I finish the job" or "never").

As there are cultural differences in the perception and measurement of time, with the help of different instruments, before the start of a negotiation with business partners from other countries, the values, attitudes and customs in that country should be carefully checked. Among the tools used to measure the time we remember: solar clocks, lead wire, hourglass, water clocks, astrolabe, Chinese watches based on the firing speed of some calibrated wood sticks.

* (https://dorinadanila.com/2015/08/25/limbajul-timpului/)

Time is considered to be the most important stress generator factor and, although in small quantity it has the motivation effect, in combination with professional dissatisfaction, has been associated with various conditions such as hypertension, hypercholesterolemia and premature ageing. 
The efficient use of working time and the use of this resource to communicate implies that a person has certain traits: capacity to set priorities, memory, flexibility, spirit of observation, skills to contact, maintain and cultivate amicable relationships, as well as effort capacity. Due to improper use of this precious resource called "Time", different methods of efficiency and optimization have been incurred. Thus, time is also a tool whereby people can become more productive both professionally and personally, due to the appropriating of a set of principles, practices, skills and systems that help to self-discipline them. All methods of efficiency and optimization of time are seen by specialists/managers from the perspective of time management, which leads to improved quality of life.

Time management begins with the management of the activities themselves, daily according to the priorities of each individual, contributing to the appropriability of skills, what goes from minimal efforts to self-discipline, what can help you reach your goals, set priorities, create an overview of your tasks, communicate better, delegate, develop your creativity, better adapt to change, make the most of your time, and make the most of your life Improve the quality of your life and work colleagues.

* (https://www.la-psiholog.ro/info/ Time-Management)

To realize both the importance and significance of the variable "time" and the strengthening of perception based on the ideas outlined above, I propose the following quote:

"Do You love life?

Then do not squander like a reckless guy, for from time to life is made! "

(Quote: Benjamin Franklin)

* (www. Career development. com > Media > Files > Time management-course)

\subsection{Silence Language}

The principle of modern communication was formulated after World War II. One of the founders of this model, Norbert WIENER, defines cyber as "science of Control and communication" as it is believed that relationships between the component parts of an object are more important than their content; In this idea, the meaning occupies a second place in relation to the structure, the information opposes disorderly and communication is the remedy for entropy.

As modern ideology, communication is a reiterated confirmation of individuals in their reciprocal position of receptors, a way to establish secure limits for some people; From here the paradox is born, underlined by David le Breton (2001) a society "in which individuals communicate much, but rarely meet."

It also treats and explains, in the volume appeared in 1997, Du silence, aspects such as: silence in conversation, disciplines, manifestations and spirituality of silence, etc., explaining the mechanisms of 
this language. If until a long time ago it was believed that silence and speech were antonym, the previously remembered book would change that assertion, for which the speech arises from silence, so that "The word vibrates on the intensity of silence" says David le Breton. So, we can only agree with the French sociologist and say that the basis of the communication is silence and that even if it is silent, the man still communicates.

*(https://evelinataralunga.wordpress.com/2014/03/27/About-language-silence -du-silence-david-lebreton-1997/);

Media or communication networks are a permanent interruption of the silence of life. The technical proliferation of the word sometimes makes him inaudible, interchangeable, dislikes his message, or requires special attention to be heard in the jamming of the sense of our society. If in modern communication silence has an increasing attraction, then it has no value in the face of violence or dictatorship, this case she becomes a figure of complicity and inability.

Therefore, the meaning of the word or silence can only be perceived according to the context which determines its participation. The meaning can be muffled by the noise and put in the value of silence, but also the reciprocal is valid, because the meaning of a word is never absolute, but is depending on how it impresses the auditor.

In Latin the distinction between two forms of silence is distinguished: silence is an active verb whose subject is a person and indicates termination or absence of speech with reference to a man. Silage is an intransitive verb that applies not only to humans but also to nature, to objects and to animals; He soon designates the silence, a calm tonality of the uninterrupted presence of no noise.

Silage and silence alternate and participate in the game of meaning in the relentlessly movements of the conversation; they make it necessary to pause so that the tongue does not choke on the words too. In the absence of silence, the communication is unthought; She would get into a continuous stream of words that would condemn speech to the impossible since the time of issuance.

By introducing a beneficial distance, a principle of self control, attention to the community, silence strengthens the social relationship and corrects the excess language. Silence is the range required by the modulations of the exchange, the breath itself of the meaning, but it has no capacity to signify only by its form. Silence is an ambiguous power. She never sends to a petrified significance, her travels are a response to the social movement of the meaning.

Refraining from the word often expresses the attempt to retain control over the interaction; It's an observation, listening attitude. It allows the individual to pursue the evolution of events pending the favorable moment without betraying their eventual vulnerability or doubts. It also requires self-control to avoid tensions with each other. 
Silence as a refusal, due to suspending the ordinary communication by word, is a positive act against social conventions; It is directed "either against the social discourse to which the subject recuse the stereotypical dimension, or against the interlocutor refusing the communication offer" (Van Den Huevel, 1985). Silence can be about the silences of the words of an individual who cannot find any interlocutor.

Silence has been assimilated little by little over the last few decades, as a commercial reference in the tourism promotion of a region, of excursions.

Tour-operators and travel agencies capitalize on silence when daily life is harassed by noise. Becoming rarer, harassed from all sides, silence turns into a special commercial value. It happens that product manufacturers buy beaches of silence in a broadcast program and provide them to the targeted audience. Silence is transformed into moral, commercial, tourist, ecological wealth, etc. Endangered species, its price climbs a day that passes and gives rise to a more or less effective and interesting protection attitude.

The silences become high and thanks to nonverbal and paraverbal indicators, such as the sighting, the inspiration and the expiration, the gaze, the attire, the left head, the distinguished body as in a sign of abandonment. If we were to observe the silence of our close interlocutors, then we might find that some know how to shut up in a more expressive way than others, even ourselves we do not always shut the same. Very illustrative is the case for actors, who can express themselves by being in the most complicated, refined, pretentious and eloquent states. And teachers (those with talent and charisma, of course) are an interesting example: they know to express through pauses placed in their place, by silence, through gestures and glances, feelings and affections discreet and intimate at the same time, but so convincing and through it can be made so easily heard and listen.

* (https://cafe-psychologique.md /About-language-silence /)

What do we actually learn by silence? By silence we learn obedience, empathy, balance, knowledge, awareness rising. Silence, put at the right place and time, urges dialogue, creativity and expressiveness. And by all this, it contributes to the enrichment of the communication register, whether it is interpersonal communication or public communication.

* (https://cafe-psychologique.md/ About-language-silence /)

In conclusion, we need to be careful, as far as possible, and to know when to talk and when to shut up. And most of the time, to shut up is the best choice because it leaves room for the cognitive process, but sometimes it can also disadvantage you, depending on the context of the situation. That is why it is indicated that in everyday life a balance between words and silence is preserved, adapting to the different situations in which we are.

*(https://evelinataralunga.wordpress.com/2014/03/27/d/silence-a-form-of-communication-david-lebreton-1997/) 
The prose of William Saroyan, Wanderer, poor and burned of longing.

Revives a scene from the childhood of the American writer. An uncle of his or came into the house with an Arab, coffee and tobacco. They both remained in a row in an incredible silence, with a sense only to them.

Confused, the child asks his mother:

'Well, what did they do?

Well, they talked

No, they didn't talk. How can you talk if you don't say words?

Well, that's right, you speak speechless. That only we all speak without words

Then what are the good words for?

Too good they never are. Often, I hide what it really is to say and you don't want others to know.

And they're talking? Ask the child again

I think so, Mom says. I don't open my mouth, but I talk all the time and they don't need words.

And you think I know what I'm talking about?

Of course, mom says»

This fragment of prose that received the Nobel prize reflected the Inter-humane communication without words.

\section{CONCLUSIONS}

In conclusion, the communication is the instrument that underpins all processes, interactions and Interhuman relations, whether we speak of verbal, non-verbal and paraverbal communication, as well as the languages used. Which is why I have deepened both the language of silence and of the time which are means of non-verbal communication. As research methods we used the method of document analysis and comparative analysis method.

\section{REFERENCES}

Aristotle, O. (1997). IRI Publishing House, Bucharest

Cuilenburg, J.J., (1991). Communication Science, Romanian version and introductory study of Tudor Olteanu, Bucharest, Humanitas

Le Breton, D., (2001). About silence, Bucharest, ALL

Marin, A.. (1987). Babylon Information, Bucharest, Ed., Politics 
Mc Quail, D., (1999). Communication, Translation by Daniela RUSU, Preface by loan DRĂGAN, The European Institute

Prutianu, Ș. (1998). Communication and negotiation in business, lasi, Polirom

Prutianu, Ș. (2004). Communication skills Training, lasi, Polirom

Stanton, N. (1995). Communication, Bucharest, publishing company Science and Technology

*** information, programming. Anthology, preface and Notes by Victor Ernest MAŞEK, publishing house Scientific, Bucharest, 1972.

* * * Larousse de poche, Paris, 1994

* * * Aesthetic Magazine, No., July, 2000.

https://dorinadanila.com/Time-language / Retrieved August 25, 2015

https://www.la-psiholog.ro/info/ Time-Management, Retrieved September 25, 2019

www. Career development. com > Media > Files > Time _ management-Course Retrieved September 25, 2019

https://evelinataralunga.wordpress.com/About-language-silence-du-silence-david-le-breton-1997/.

Retrieved March 27, 2014

https://cafe-psychologique.md/ silence-a-form-of-communication /. Retrieved June 27, 2019 